\title{
Memória Social \\ a brincadeira dos cocos na comunidade quilombola Caiana dos Crioulos-PB
}

\author{
Eurides de Souza Santos ${ }^{1}$
}

Resumo

O presente artigo discute o papel da memória social na construção e manutenção de atividades culturais. A pesquisa focalizou a brincadeira dos cocos em Caiana dos Crioulos, uma comunidade remanescente dos quilombos, localizada no Estado da Paraíba. Utilizando conceitos teóricos da Antropologia, Sociologia e Etnomusicologia, o presente texto argumenta que a memória social constitui um vigoroso campo para a negociação, transformação e manutenção de valores socioculturais.

\section{Palavras-chave}

Memória social, brincadeira dos cocos, Caiana dos Crioulos, comunidades quilombolas, música tradicional brasileira.

Recebido em 26 de agosto de 2013

Aprovado em 12 de fevereiro de 2014

SANTOS, Eurides de Souza. Memória Social: a brincadeira dos cocos na comunidade quilombola Caiana dos Crioulos-PB. Revista do Instituto de Estudos Brasileiros, Brasil, n. 59, p. 261-282, dez. 2014. D0I: http://dx.doi.org/10.11606/issn.2316-901X.v0i59p261-282

1 Universidade Federal da Paraíba (UFPB, João Pessoa, PB, Brasil). 


\title{
Social Memory \\ the Dance of Cocos from Creole Caiana in \\ Paraíba
}

\author{
Eurides de Souza Santos
}

\section{Abstract}

This paper discusses the role of social memory in constructing and maintaining cultural activities. The research focused on the dance of cocos from Creole Caiana, a remnant community of quilombos, located in the State of Paraíba, Northeastern Brazil. Using theoretical concepts from Anthropology, Sociology and Ethnomusicology, this article argues that social memory constitutes a vigorous field for the negotiation, transformation and maintenance of socio-cultural values.

\section{Keywords}

Social memory, the dance of cocos, Creole Caiana, remnant community of quilombos, Brazilian traditional music. 


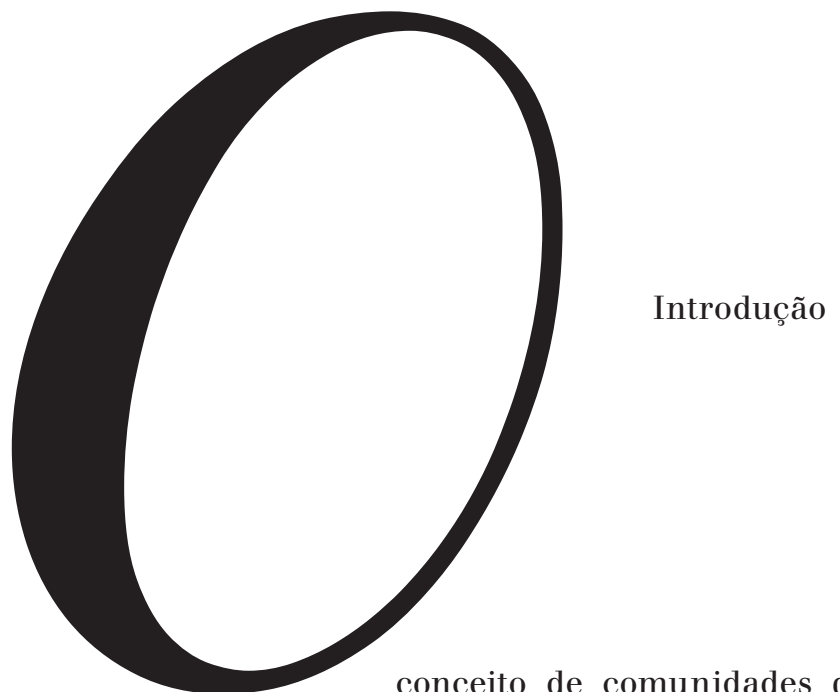

conceito de comunidades quilombolas, ainda que inspirado em uma realidade secular, é relativamente recente e tem sido concebido, na contemporaneidade brasileira, com base na autodefinição identitária relacionada a uma ancestralidade negra, com sentido coletivo. De acordo com o Ministério do Desenvolvimento Social,

são grupos étnico-raciais, segundo critérios de autoatribuição, com trajetória histórica própria, dotados de relações territoriais específicas e com ancestralidade negra relacionada com a resistência à opressão histórica sofrida, conforme Decreto $n^{0} 4887 / 03 .^{2}$

Além da crucial questão referente ao redimensionamento do território geográfico envolvido, a criação de comunidades remanescentes dos quilombos implica a ressignificação de valores sociais, culturais, religiosos, econômicos e ambientais, de forma a se construir um status de legitimidade, consonante com as leis, regras e políticas que as estruturam. Implica, igualmente, o reordenamento das relações de poder internas e externas, de forma a se construir um diálogo possível entre os grupos sociais e autoridades envolvidos. No presente texto, aproximo-me da comunidade quilombola Caiana dos Crioulos, pelo campo da memória social, buscando investigar os processos de interpretação e ressignificação da brincadeira dos cocos, enquanto prática cultural cuja ancestralidade

2 Cf. MINISTÉRIO DO DESENVOLVIMENTO SOCIAL: Comunidades Quilombolas. Disponível em: http://Www.mds.gov.br/segurancaalimentar/ povosecomunidadestradicionais/quilombolas. Acesso em: zo jun. 2014. Não é propósito do presente artigo aprofundar-se na questão das comunidades remanescentes dos quilombos. 
negra tem sido reivindicada nos discursos locais. Destaco nesse contexto o papel da liderança da brincadeira dos cocos, as mestras cirandeiras, como representantes da memória social local.

Caiana dos Crioulos é uma comunidade paraibana, de maioria negra, que recebeu o título de "remanescente dos quilombos" em 2005. De acordo com Fialho, os estudos para fins de compor o projeto de mapeamento revelaram um grupo social e politicamente envolvido com a questão quilombola.

Apesar de, em 1998, já se ouvir falar de outras comunidades negras rurais no Estado, foi Caiana que veio primeiro colocar em xeque a assunção da categoria de quilombola num complexo contexto fundiário em que se sobrepõem áreas de assentamento do Incra, propriedades privadas e um território fundado na concepção de ancestralidade e tradição negra. ${ }^{3}$

A reivindicação da 'ancestralidade negra', verificada no aspecto do direito fundiário pode ser também observada no âmbito das formas de sociabilidade cultivadas na comunidade. Referindo-se à brincadeira dos cocos, a cirandeira Edite José da Silva, (Dona Edite, 70 anos), afirma o seguinte: antigamente [...] o pessoal se divertia só de coco de roda, [...] dos antigos, dos antepassados". Severina Luzia da Silva, (Dona Cida, 48 anos), também cirandeira local, afirma que "antigamente não tinha outra diversão que não fosse essa. [E destaca] Só lembro que o povo se reunia nas festas e ficava dançando e cantando a noite toda. E eu lá com eles". ${ }^{5}$ A brincadeira dos cocos é uma manifestação cultural coletiva, composta de canto, dança e acompanhamento instrumental, que se caracteriza como lazer comunitário e como espetáculo artístico. Enquanto expressão da tradição cultural local, a brincadeira dos cocos disputa espaços de legitimidade no campo da memória social local, em meio aos processos de transformação e na convivência com formas diversas de expressões artísticas, de sociabilidade e de divertimento.

3 FIALHO, Vania. Caiana dos Crioulos: revisitando um quilombo do brejo paraibano. Disponível em: http://www.koinonia.org.br/OQ_temp/pop_ensaior5.htm. Acesso em: 18 nov. 2012.

4 SILVA, Edite José da. Depoimento. In: CAIANA DOS CRIOULOS: ciranda, coco de roda e outros cantos. Projeto memória musical da Paraíba, vol. ı. Produção de Socorro Lira. Manaus: Indústria da Amazônia, 200z. 1 CD.

5 SILVA. Severina Luzia da. Depoimento. In: QUILOMBO de Caiana dos Crioulos reverencia sua história nas rodas de ciranda e no coco-de-roda. Disponível em: http://ombudspe.org.br/brasilquilombola/?p=13. Acesso em: 20 mar 2013. 


\section{Memória Social}

As funções da memória e suas relações com as identidades, valores e tradições socioculturais permeiam os trabalhos de estudiosos, em campos teóricos diversos, desde os antigos gregos aos seminais estudos desenvolvidos nos fins do século XIX e início do XX por Freud ${ }^{6}$, Nietzsche $^{7}$, Bergson ${ }^{8}$ e Durkheim ${ }^{9}$. No entanto, foi Maurice Halbwachs quem desenvolveu a noção de uma memória coletiva, como conjunto de recordações - valores e imagens - formando elos significativos entre o passado e o presente de um grupo social. Para o autor, é na sociedade que as pessoas adquirem, reconhecem e reconstroem suas lembranças. Halbwachs chama a atenção para uma combinação de influências, todas de natureza social, que vão estar presentes no conceito de memória coletiva, afirmando que, "para evocar seu próprio passado, em geral, a pessoa precisa recorrer às lembranças de outras, e se transportar a pontos de referência que existem fora de si, determinados pela sociedade". ${ }^{10}$

Contemplando também a memória coletiva como conjunto de lembranças e imagens que une o passado ao presente, porém, assumindo um posicionamento mais político, Pierre Nora ${ }^{11}$ concebe a passagem da memória para a história como uma perda dramática e irreversível em relação ao passado. Segundo o autor,

A memória emerge de um grupo que ela une, o que quer dizer, como Halbwachs o fez, há tantas memórias quantos grupos existem; ela é, por natureza, múltipla e desacelerada, coletiva, plural e individualizada. A história, ao contrário, pertence a todos e a ninguém, o que lhe dá uma vocação para o universal. A memória se enraíza no concreto, no gesto, na imagem, no objeto. ${ }^{12}$

6 FREUD, Sigmund. Carta 52. In: A correspondência completa de Sigmund Freud para Wilhelm Fliess. Rio de Janeiro: Imago, 1986. Pulsões e destinos da pulsão. In: Escritos sobre a Psicologia do Inconsciente, Volume I. Rio de Janeiro: Imago, 2004 .

7 NIETZSCHE, Friedrich. A genealogia da moral. São Paulo: Moraes, 1985.

8 BERGSON, Henri. Matéria e memória: ensaio sobre a relação do corpo com o espírito. São Paulo: Martins Fontes, 2006.

9 DURKEIM, Émile. As formas elementares da vida religiosa: o sistema totêmico na Austrália. São Paulo, 2000.

10 HALBWACHS, Maurice. A memória coletiva. São Paulo: Centauro, 2006. p. 72.

11 NORA, Pierre. Entre memória e história: a problemática dos lugares. Projeto História, n. 10. São Paulo: PUC/USP, 1993.

12 NORA, Pierre. Entre memória e história: a problemática dos lugares, p. og. 
Embora seminal, a ideia de uma memória coletiva reificada como conjunto de lembranças, uma espécie de conhecimento construído e transmitido do passado para o presente, instiga questionamentos diversos, principalmente no que diz respeito aos processos envolvidos na aceitação comunal, na seletividade e nas formas de transmissão dessa memória. Uma vez que o ato de lembrar constitui uma faculdade da mente individual, "é o indivíduo que lembra", questionam-se os modos pelos quais as lembranças individuais se tornam memória coletiva, e como as memórias se generalizaram ao longo do tempo.

Nessa perspectiva, Fentress e Wickham ${ }^{13}$ alertam para os riscos de se adotar "um conceito de consciência coletiva curiosamente desconectada dos processos reais de pensamento de qualquer pessoa em particular". ${ }^{14}$ Para os autores, tal conceito torna "o indivíduo um tipo de autômato, obedecendo passivamente ao desejo coletivo interiorizado". ${ }^{15}$ Ao defender a dimensão política do campo da memória social, Moraes descarta a noção de "espaço e produtor de relações societárias, estáveis e imutáveis" e a descreve como "um vigoroso, complexo e tenso campo de disputas de sentidos em que a mobilização e a circulação dos discursos e representações são utilizadas com intensidade e possibilidades diferentes". ${ }^{16}$

Pollak observa que, no trabalho de Halbwachs, o processo de negociação para conciliar memória coletiva e memórias individuais já aparece. No entanto, "o reconhecimento do caráter potencialmente problemático de uma memória coletiva" ${ }^{17}$ vai caracterizar a inversão de perspectiva em trabalhos posteriores.

Numa perspectiva construtivista, não se trata mais de lidar com os fatos sociais como coisas, mas de analisar como os fatos sociais se tornam coisas, como e por quem eles são solidificados e dotados

13 FENTRESS, J.; WICKHAM, C. 1992 apud OLICK Jeffrey K.; ROBBIN Joyce. Social Memory Studies: from 'Collective Memory' to the Historical Sociology of Mnemonic Practices. Annual Review of Sociology, v. 24, p. 105-140, 1998, p.111. DOI: http://dx.doi. org/10.1146/annurev.soc.24.1.105

14. "A concept of collective consciousness curiously disconnected from the actual thought processes of any particular person."

15 "[...] the individual a sort of automaton, passively obeying the interiorized collective will".

16 MORAES, Nilson Alves de. Memória social: solidariedade orgânica e disputas de sentidos. In: GONDAR, Jô; DODEBEI, Vera (Org.). O que é memória social? Rio de Janeiro: Contra Capa, 2005.p. 92.

17 POLLAK, Michael. Memória, esquecimento, silêncio. Tradução de Dora Rocha Flaksman. In: Estudos Históricos, Rio de Janeiro, v. 2, n. 3, 1989, p. 4. 
de duração e estabilidade. Aplicada à memória coletiva, essa abordagem irá se interessar, portanto, pelos processos e atores que intervêm no trabalho de constituição e de formalização das memórias. $^{18}$

Paul Connerton sustenta a noção de memória social como conjunto de lembranças mantidas e transmitidas por um grupo social, porém, concentra-se nas diferentes formas, implícitas e explícitas nas quais a memória social opera. $\mathrm{O}$ autor desenvolve seus estudos dando foco a duas áreas específicas da atividade social: as cerimônias comemorativas e as práticas corporais ${ }^{19}$. Para Connerton, cada grupo saberá manter o passado na mente através da memória-hábito sedimentada no corpo. Com base nesse princípio, ele defende a eficácia da ação ritual na transmissão e manutenção da memória social, argumentando que "os ritos têm a capacidade de conferir valor e sentido à vida daqueles que os executam porque é apenas pela ação que somos capazes de reconhecer e demonstrar aos outros que de fato lembramos". ${ }^{20}$

Seguindo Connerton, Reily ${ }^{21}$ reconhece a importância do corpo como substrato cultural básico, no entanto questiona o fato de Connerton não considerar, adequadamente, as complexidades nos processos de inscrição corporal, uma vez que, de acordo com Reily, "é precisamente porque o automatismo corporal limita o escopo para avaliação crítica que o corpo é um lugar de intensa disputa pelo controle do que nele está inscrito $^{22}$. A autora se baseia na teoria dos transcritos escondidos de James Scott ${ }^{23}$, para argumentar que

A memória social de grupos subalternos carrega todas as características dos transcritos escondidos, de modo que se pode referir à 'memória social escondida', como aquela na qual eventos do

18 POLLAK, Michael. Memória, esquecimento, silêncio.

19 CONnERTON, Paul. Como as sociedades recordam. 2. ed. Tradução de Maria Manuela Rocha. Lisboa: Celta Editora, 1999.

20 CONNERTON, Paul. Como as sociedades recordam, p.8.

21 REILY, Suzel Ana. To Remember Captivity: the Congados of Southern Minas Gerais. Latin American Music Review, v. 22, p. 4-30, 2001. p. 6. DOI: http://dx.doi. org/10.1353/lat.2001.0009

22 "It is precisely because bodily automatism limits the scope for critical evaluation that the body is a site of intense struggle over the control of what gets inscribed upon it”. REILY, Suzel Ana. To Remember Captivity: the Congados of Southern Minas Gerais, p. 5 .

23 SCOTT, James. Weapons of the Weak: Everyday Forms of Peasant Resistance. New Haven: Yale University Press, 1985. 
passado, apontados como dignos de serem lembrados, são precisamente aqueles que aumentam a consciência e a crítica sobre as circunstâncias presentes. ${ }^{24}$

A memória social escondida, segundo Reily, é mais eficientemente transmitida e sustentada através da performance. Para ela, a música e a dança constituem eficientes dispositivos mnemônicos para a preservação da memória social escondida ${ }^{25}$.

Com base nas discussões apresentadas até aqui, assumimos, no presente artigo, uma definição de memória social como campo de dimensão política, no qual se encontram em disputa os valores mais caros e mais estimados por um grupo social. As práticas da performance, incluindo a dança, a música, as narrativas e as encenações, ocupam posição privilegiada na memória social, porque se traduzem como eficientes recursos para a mobilização e ressignificação dos valores cultivados socialmente.

\section{Caiana dos Crioulos: descrição do lugar}

A comunidade de Caiana dos Crioulos está localizada na zona rural da cidade de Alagoa Grande ${ }^{26}$, Estado da Paraíba. Os moradores locais explicam que a denominação Caiana vem de uma espécie de canade-açúcar cultivada na agricultura familiar e nos engenhos da região. No entanto, não há concordância entre eles quanto ao aditivo "dos Crioulos". Uma das explicações mais aceitas é a de que o termo passou a ser utilizado por pessoas de fora, quando queriam diferenciar essa comunidade de outra existente na região denominada Caiana do Agreste. De acordo com depoimentos dos moradores locais, no passado toda aquela região se chamava Caiana. A partir dos anos 70, do século passado, aquelas terras foram divididas em três partes, e o aditivo "dos Crioulos", já utilizado por pessoas de fora, se tornou oficial.

24. The social memory of subaltern groups bears all the hallmarks of hidden transcripts, such that one could refer to "hidden social memory," in which the events of the past that are singled out as worthy of remembering are precisely those which heighten awareness of and critique present circumstances. REILY, Suzel Ana. To Remember Captivity: the Congados of Southern Minas Gerais, p. 6.

25 REILY, Suzel Ana. To Remember Captivity: the Congados of Southern Minas Gerais, p. 6

26 Alagoa Grande se destaca na cena cultural paraibana por ser a cidade onde nasceu o cantor e compositor Jackson do Pandeiro. Sua mãe Flora Maria da Conceição (Flora Mourão) foi uma cantadora de coco conhecida na região. Cf. MOURA, Fernando; VICENTE, Antônio. Jackson do Pandeiro: o rei do ritmo. São Paulo: Editora 34, 2001. 


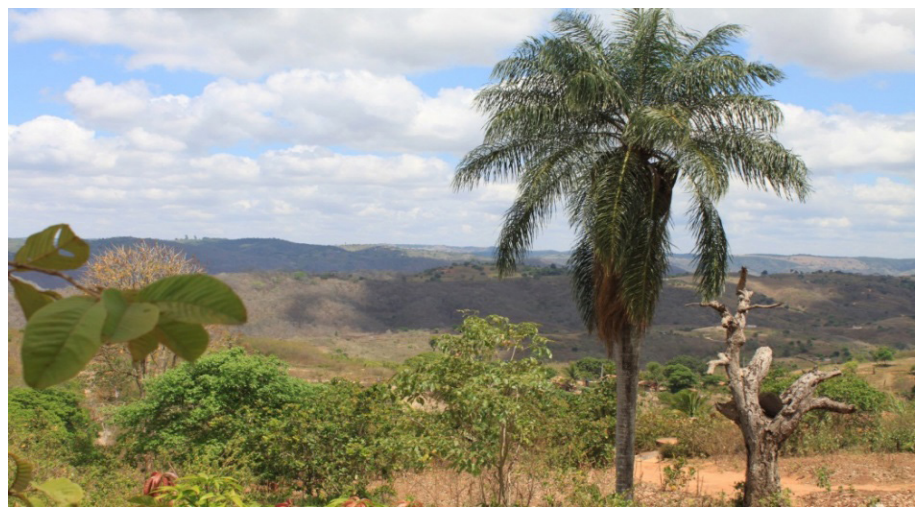

Figura 1: Imagem das terras de Caiana dos Crioulos. Foto de Marília Cahino Bezerra. Junho de 2012.

Para chegar à comunidade, saindo de Alagoa Grande ${ }^{27}$, o viajante enfrenta doze quilômetros de relevo bastante irregular, cuja estrada de barro fora acrescida de cascalhos para viabilizar o transporte por meio de animais, motocicletas e automóveis. Ao longo do caminho, avista-se uma paisagem de matas e serras que, nos últimos anos, tem sido utilizada para o turismo rural, por oferecer trilhas para caminhadas, cavalgadas, ciclismo e motociclismo. A paisagem sonora local mistura os sons da natureza às músicas que vêm dos rádios nas residências. Raramente se ouvem conversas ou movimentos das pessoas dentro das casas.

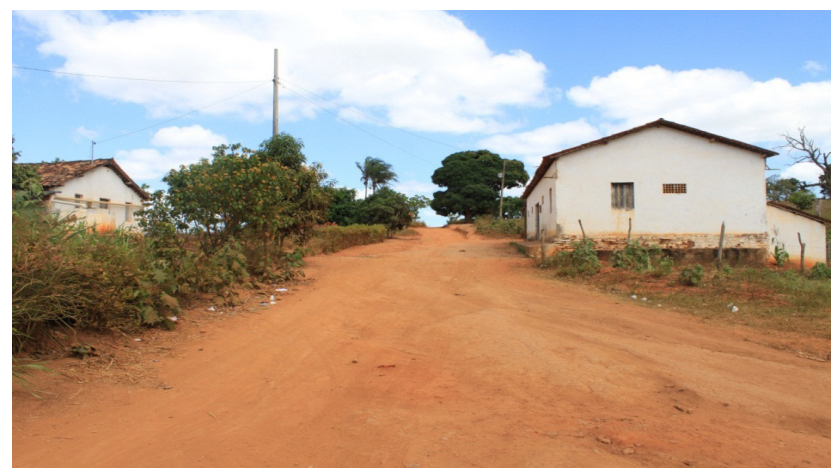

Figura 2: Disposição das residências de Caiana dos Crioulos. Foto de Marília Cahino Bezerra. Junho de 2012.

27 Cerca de 120 quilômetros da capital João Pessoa. 
A comunidade é constituída por cerca de 140 famílias $^{28}$, cujas residências são separadas por áreas de roçados nos quais se cultiva a agricultura familiar e criam-se animais de pequeno porte, como bode, galinha e porco. Os cereais e tubérculos, tais como o milho, o feijão, a macaxeira, o inhame e a batata doce servem para a alimentação local, juntamente com as árvores frutíferas próprias da região. Parte dessa produção serve também para complementar a renda de algumas famílias que, aos sábados, dirigem-se ao centro de Alagoa Grande para comercializar seus produtos.

O "centro" da comunidade, assim chamado pelos moradores, é formado pela paróquia de Santa Luzia, um posto de saúde e uma mercearia. Os demais estabelecimentos públicos, distribuídos nos domínios da comunidade, compreendem uma escola municipal de ensino fundamental, algumas congregações evangélicas e uma associação de moradores, onde acontecem as reuniões de interesse comum. O transporte coletivo é feito através de vans particulares e das motocicletas existentes na grande maioria das residências. O provimento dos demais serviços, a exemplo do ensino médio e superior, comércio, bancos, feira livre, cinema, entre outros, é feito em Alagoa Grande ou em cidades próximas. Em geral, os jovens de Caiana migram para os centros urbanos, de dentro e de fora do Estado, em busca de trabalho e alternativas de sobrevivência.

Como acontece em grande parte das comunidades rurais brasileiras, os moradores de Caiana dos Crioulos dividem as dificuldades relacionadas à falta de água tratada, ausência de sistema de esgoto, ausência de serviço hospitalar, ausência de transportes públicos, estradas quase intransitáveis, entre outros problemas, com as facilidades proporcionadas pela tecnologia dos eletrodomésticos, das antenas parabólicas, dos aparelhos celulares, dos computadores, da internet e das motocicletas.

Se, por um lado, o recebimento do certificado de 'remanescentes dos quilombos' em 2005, soma-se às conquistas da comunidade ao longo das últimas décadas ${ }^{29}$, por outro, esse certificado representa mais um instrumento para o recomeço das lutas pela apropriação definitiva da terra e por melhores condições de vida no local. Nesse contexto, as

28 Dado da Associação de apoio às comunidades afrodescendentes (AACADE) e da Coordenação das comunidades negras e quilombolas (CECNEQ). Disponível em: http://quilombosdaparaiba.blogspot.com.br/search/label/Caiana-info. Acesso em: 20 jun. 2014 .

29 Apenas para citar duas: a implantação da associação de moradores em 1986 e a implantação da escola de ensino fundamental Firmo Santino da Silva, em 2001. 
mobilizações em torno da questão quilombola e a autodefinição de identidade fundada na ancestralidade negra trouxeram, inevitavelmente, a brincadeira dos cocos para o centro dos discursos referentes à memória social em Caiana dos Crioulos.

\section{Brincadeira dos cocos: seletividade, alianças e inovações}

Retomemos a narrativa de Dona Edite, já mencionada acima:

Antigamente não existia forró, não existia som pro pessoal dançar, que a coisa agora tudo é som. Antigamente era só zabumba, pife; a outra tradição que tinha era concertina nos casamentos, violão, tocador de viola. Era isso que existia. Aí pronto, aí o pessoal se divertia só de coco de roda, rezando novena com procissão. Quando terminava aquela procissão, vamos fazer uma brincadeira de coco de roda. Aí, nós ficava [sic] brincando coco de roda, dos antigos, dos antepassados, e aí eles deixaram a semente pra nós, e nós estamos brincando coco de roda. ${ }^{30}$

O contexto em que se situa essa narrativa é o período da gravação do primeiro CD do grupo de ciranda e coco de roda de Caiana dos Crioulos, lançado em 2003, como parte do "projeto memória musical da Paraíba". Sobre essa gravação, Luiz comenta que embora o CD tenha sido gravado na comunidade, as cirandeiras não cantaram de forma espontânea. Segundo ele, "todas elas tiveram que ensaiar bastante para realizar a gravação". ${ }^{31}$ A fala de Dona Edite, acima citada, antecede a primeira faixa musical do CD e se revela crucial para o momento histórico em que se reivindicam elementos definidores da identidade quilombola. No seu discurso, a presença do coco de roda na comunidade e a ligação deste com os antepassados (negros) constituem marca legitimadora de uma ancestralidade negra.

Porém, ao afirmar que a brincadeira dos cocos vem dos antigos moradores das terras em disputa e excluir certas práticas musicais desse

zo SILVA, Edite José da. Depoimento. In: CAIANA DOS CRIOULOS: ciranda, coco de roda e outros cantos. Projeto memória musical da Paraíba, vol. ı. Produção de Socorro Lira. Manaus: Indústria da Amazônia, 2003. 1 CD.

31 LUIZ, Janailson Macêdo. Das ressignificações do passado: as artes da memória e a escrita da história da comunidade remanescente de quilombos Caiana dos Crioulos, Alagoa Grande - PB. 2013. 191f. Dissertação (Mestrado em História) - Universidade Federal de Campina Grande. Campina Grande, 2013. 
contexto histórico, a cantadora assume uma posição de seletividade, que é uma estratégia própria do campo da memória social. Em contextos específicos, essa memória, que atua no sentido de viabilizar estruturas sociais, seleciona, ordena e classifica alguns fatos, enquanto esquece, silencia e/ou exclui outros ${ }^{32}$. Outrossim, ao tempo em que a cantadora exclui elementos como o 'forró' e o 'som'33 da vida sociomusical dos antigos moradores, firmando a legitimidade do coco de roda, ela também omite uma importante e antiga aliança entre o coco de roda e a ciranda, que são os principais gêneros musicais formadores da brincadeira. A ciranda, que também dá nome à brincadeira e está presente no título do CD, não aparece na narrativa citada. Em um depoimento mais informal, Edinalva Rita do Nascimento (Nalva, 28 anos), neta do mestre cirandeiro João Maria $^{54}$, relata:

todo ano, na véspera de São João, tinha o terço na casa do meu avô e depois a ciranda, que ia até às seis ou sete horas da manhã". Enquanto tivesse gente, a ciranda acontecia na casa dele. Podia ter forró ou outra festa acontecendo na comunidade. ${ }^{35}$

Diferentemente do que ocorre com os cocos, cujos estudos buscam possíveis origens na memória coletiva - com base em fontes orais, as referências à ciranda, na literatura, não deixam dúvidas sobre sua origem portuguesa ${ }^{36}$. No que diz respeito às características de cada um desses gêneros, (por exemplo, a umbigada e o movimento solto e rápido no coco de roda e, no caso da ciranda, o movimento mais lento e de mãos dadas), quando se considera a brincadeira como um todo, essas características se definem melhor pelas suas funções na performance do que exatamente pelas diferenças coreográficas entre os dois gêneros. De acordo com a cirandeira Vó Mera, a alternância entre as danças funciona como descanso para os brincantes porque "o coco é

$3^{2}$ MORAES, Nilson Alves de. Memória social: solidariedade orgânica e disputas de sentidos.

33 Ela se refere aos aparelhos de reprodução e amplificação sonora.

34 João Manoel do Nascimento (†1995). Último pifeiro e cirandeiro das gerações masculinas de mestres. Há três décadas a brincadeira dos cocos, em Caiana dos Crioulos, tem sido liderada por mulheres.

35 NASCIMENTO, Edinalva Rita do. Depoimento. Entrevistadora: Eurides de Souza Santos. Caiana dos Crioulos: Escola Municipal Firmo Santino. [nov. 2012].

36 ANDRADE, Mário de. Dicionário Musical Brasileiro. São Paulo, Itatiaia, 1989. CASCUDO, Câmara. Dicionário do folclore brasileiro. 9. ed. São Paulo: Ediouro, [1998?]. 
mais aperreado". ${ }^{37} \mathrm{Na}$ performance, o coco de roda e a ciranda compartilham a instrumentação, as letras, as melodias, entre outros aspectos relativos à sociabilidade.

Da aliança entre a ciranda e o coco de roda vêm as maneiras de convidar as pessoas para a brincadeira - 'vamos fazer uma ciranda' ou 'vamos fazer uma brincadeira de coco de roda'. Da mesma forma, os termos que definem o líder podem ser 'mestre cirandeiro', 'mestra cirandeira' ou apenas 'cirandeiro' e 'cirandeira'. As designações de 'mestre ou mestra coquista' também são comumente utilizadas entre as comunidades que detêm a brincadeira. A tradição dos cocos revela ainda importantes alianças, a exemplo da realização da brincadeira após as novenas e procissões, bem como as parcerias com a música popular urbana. Hall lembra que "a tradição é um elemento vital da cultura, mas ela tem pouco a ver com a mera persistência das velhas formas. Está muito mais relacionada às formas de associação e articulação dos elementos" ${ }^{38}$ com as diferentes práticas.

De atividade voltada para o lazer comunitário e eventuais participações em eventos políticos até a década de1990, a brincadeira dos cocos, em Caiana dos Crioulos, passou por importantes ressignificações na década de 2000, quando os espaços de performance, externos à comunidade, foram ampliados e as narrativas de reforço à ancestralidade negra encontraram maior ressonância, principalmente, no meio acadêmico. A implantação das políticas públicas de cultura, em nível estadual e nacional, também contribuiu para essa nova realidade.

Foi a partir da década de 2000 que o grupo de coco de roda e ciranda passou a apresentar-se, com maior frequência, em eventos culturais, políticos e acadêmicos. Por sua vez, o terreiro comunitário, onde se dança regularmente, passou a funcionar também como estúdio de gravação. Entre os trabalhos produzidos pelo grupo de ciranda e coco de roda, nesse período, destacam-se a gravação do CD "Caiana dos Crioulos, ciranda coco de roda e outros cantos", lançado em $2003^{39}$; a participação no CD "Cantigas do bem-querer", também lançado em $2003^{40}$; a participação no CD "Responde a roda outra vez", gravado em 2004."; a participação no CD/DVD "A barca: trilha, toada e tripé",

37 SILVA. Domerina Nicolau da. [Vó Mera] Depoimento. Entrevistadora: Eurides de Souza Santos. João Pessoa. [nov. 2010].

38 HALL, Stuart. Da diáspora: identidade e mediações culturais. Organização: Liv Sovik. Belo Horizonte: Editora UFMG, 2011.

39 CAIANA DOS CRIOULOS: ciranda, coco de roda e outros cantos.

40 Trabalho autoral da cantora e compositora Socorro Lira. Cf. www.socorrolira.com.br.

41 Coordenação de Carlos Sandroni, Maria Ignez N. Ayala e Marcos Ayala. 
lançado em $2005^{42}$; e a gravação do segundo CD, intitulado, "Desencosta da parede", ${ }^{43}$ lançado em $2007^{44}$.

Este último trabalho, o CD "Desencosta da parede" contou com a participação do cantor Chico César na faixa de número três. Faremos uma análise musical dessa faixa, cujo título é "Corresse, nego", visando refletir sobre possíveis processos de inovação musical, resultantes dessa performance em parceria com um artista oriundo de um contexto musical distinto. Chico César, compositor e cantor paraibano do município de Catolé do Rocha, tornou-se conhecido na mídia fonográfica a partir de 1995, quando lançou seu primeiro CD. O coco de roda "Corresse, nego" sugere uma situação de fuga de um escravo. Curiosamente, essa é uma das poucas músicas, do repertório tradicional dos cocos de roda de Caiana dos Crioulos, que fazem alusão à escravidão. De acordo com os moradores locais, até décadas passadas, não se falava abertamente sobre esse assunto. Trataremos dessa questão adiante.

Solo - Corresse, nego, corresse, com medo de apanhar?

Coro - Será a barra do dia, será o dia, será?

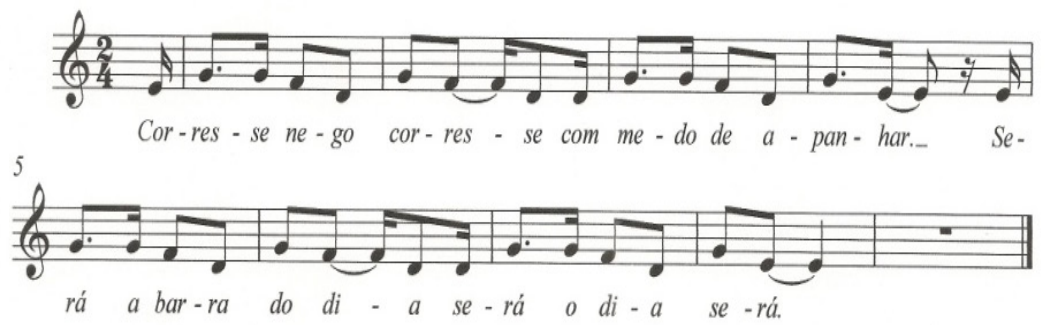

Exemplo 1

A forma 'regular' de cantar o coco de roda é o solo (pergunta) seguido do coro (resposta). Essa estrutura é repetida por diversas vezes até que a solista inicie outra música. Na gravação em análise, o coco é iniciado nessa forma 'regular' e repetido sete vezes, até a entrada da voz de Chico César. Ainda na quarta repetição, Chico César sugere um pulso,

42 Cf. www.barca.com.br.

43 CAIANA DOS CRIOUlOS. Desencosta da parede: ciranda e coco-de-roda. Caucaia: Nordeste Digital Line S/A, 2008. 1 CD.

44. Desde 2007, Caiana dos Crioulos possui dois grupos de coco de roda e ciranda, como resultado de cisão entre as lideranças internas. Um grupo é liderado por Dona Edite e o outro por Dona Cida. 
no tempo forte, batido com palmas e pés, que é imediatamente seguido pelos instrumentistas e pelo coro. Enquanto o grupo segue cantando e tocando com base nesse pulso, o cantor faz variações rítmicas, como nos exemplos que seguem.

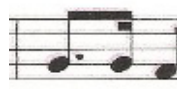

\section{Exemplo 2}

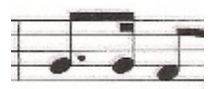

\section{Exemplo 3}

Ao tempo que une todo o grupo em um mesmo pulso, essa batida de palmas e pés, no tempo forte, modifica uma das principais características do coco de roda, que é sua forma mais ou menos livre de dança individual, mesmo estando na roda. Em geral, os brincantes subjetivam o tempo forte dado pelo zabumba, realizando movimentos coreográficos individuais ou em duplas. Na situação em análise, ouvem-se as batidas das palmas e pés na forma de um grande uníssono. O ambiente sonoro, que serve de fundo para esse canto, é composto de falas, risadas e ruídos vindos do movimento das pessoas ao redor.

A partir da oitava repetição, Chico César assume o papel de solista, momentaneamente, até que Dona Edite volta a cantar com ele. Ele não inicia seu canto com a pergunta (solo), mas começa cantando o responso (coro) “Lá vem a barra do dia, será o dia, será?", retornando à forma 'solo-coro', em seguida. Ao longo da sua participação, o cantor cria variações rítmicas que são por ele repetidas por diversas vezes. A partir da performance com Chico César, as cirandeiras de Caiana dos Crioulos têm mantido a forma de cantar introduzida na gravação.

As mudanças ou inovações nas manifestações tradicionais são ações do campo da memória social, que se configuram como formas de ressignificação e reposicionamento dos elementos vivos da cultura. Bruno Nettl sugere um conceito de

'Energia musical' como uma constante dentro da qual mudanças e continuidades de estilo, repertório, tecnologia e aspectos dos componentes sociais da música são manipuladas por uma 
sociedade, a fim de acomodar as necessidades tanto de mudança quanto de continuidade. ${ }^{45}$

Essa "energia" na brincadeira dos cocos de Caiana dos Crioulos tem sido renovada, entre outros aspectos, através das alianças e parcerias que são históricas. Por vezes, nos processos de ressignificação os atores sociais excluem e omitem alguns elementos enquanto trazem para o centro aqueles que devem ser notados. Assim, a pouca referência à questão da ancestralidade negra, no repertório tradicional, revela aspectos de um tempo passado em que esse "valor" da memória coletiva local não estava revelado nas letras (ou, não podia estar revelado), mas certamente, fora experimentado na performance por aqueles que fazem a brincadeira. Reily destaca que a "memória social escondida" diz respeito àqueles valores sociais do passado que são dignos de serem lembrados porque aumentam a consciência da experiência presente. Esses valores sociais são experimentados na performance.

Nas últimas décadas, as cirandeiras e cirandeiros paraibanos têm criado novas músicas que trazem referências à ancestralidade negra, aos tempos da escravidão, ao racismo, entre outros temas, além de manter os assuntos do repertório tradicional (o amor, a amizade, a família e fatos do cotidiano). Em Caiana dos Crioulos, as questões relativas à negritude e ao racismo estão evidenciadas no repertório mais recente que também aborda as lutas históricas envolvendo os trabalhadores dos engenhos de cana da região. Um exemplo disso é a ciranda composta por Dona Edite ${ }^{47}$, para homenagear a ex-sindicalista Margarida Maria Alves, assassinada em Alagoa Grande, em 1983. A letra diz o seguinte:

Bom dia a todos vocês,

Hoje aqui nesse lugar,

Sou Edite cirandeira,

Vim aqui apresentar.

Peço aqui por gentileza

Um pouquinho de atenção,

Pra falar de uma líder

Com carinho e emoção.

45 NETTL, Bruno. O estudo comparativo da mudança musical: estudos de caso de quatro culturas. Revista Anthropológicas, ano 10, v. 17(1), 2006, p. 16.

46 REILY, Suzel Ana. To Remember Captivity: the Congados of Southern Minas Gerais.

47 SILVA, Edite José da. Depoimento. 
Essa é Margarida Alves,

Uma mulher batalhadora

Em busca pelos direitos

Ela foi uma lutadora.

Margarida foi guerreira

E lutou pelo seu povo,

Tentando encontrar caminho

Pra formar um mundo novo.

Mas o que ficou em mente,

Para nos finalizar,

Uma frase importante,

Vamos todos relembrar.

Ela sempre nos dizia,

Para todos escutar:

'É melhor morrer na luta

Do que a fome nos matar'.

Margarida se criou-se

No Agreste de Caiana,

Porém a sua cultura

Era abacaxi e cana.

Margarida Maria Alves se tornou ícone da luta e resistência dos trabalhadores das usinas e engenhos de cana da região de Caiana. Ela também é lembrada nas lutas referentes aos direitos das mulheres, a exemplo do movimento "Marcha das Margaridas". O mote "é melhor morrer na luta do que a fome nos matar", de sua autoria, tem sido repetido regularmente nas músicas e narrativas que abordam situações de opressão e escravidão.

Festa de São João de 2012: uma etnografia da brincadeira dos $\operatorname{cocos}$

24 de junho de 2012 - Dia de São João

Naquele domingo, chegamos em Caiana dos Crioulos ao meio-dia e logo ligamos para o telefone celular de Dona Edite, para que ela nos ensinasse o caminho até sua casa, onde iria acontecer a brincadeira. Foram necessárias várias ligações e várias explicativas 
por parte da mestra para que, finalmente, chegássemos à sua casa. No percurso, seguindo diferentes trilhas e caminhos, não encontramos transeuntes, apenas ouvimos o som dos rádios nas casas, em geral tocando forró ou o sertanejo romântico. Também não ouvimos, nem vimos o movimento das pessoas dentro das casas. ${ }^{48}$ Com a ajuda de um dos seus netos, que foi ao nosso encontro, chegamos à casa da mestra, já por volta das 13h40min. Ao entrarmos, cumprimentamos as pessoas que estavam na sala assistindo televisão. Do lado de fora, ouviam-se músicas do CD "Desencosta da parede", através de duas grandes caixas de som, que mais tarde seriam utilizadas para amplificar a voz da mestra ao microfone. O volume alto servia para chamar os brincantes, que foram chegando aos poucos, a pé, subindo a passos lentos a colina que leva à casa da mestra. Dona Edite explicou que a demora para o início da brincadeira se dava pelo atraso do zabumbeiro que estava tocando forró em outra localidade. A brincadeira comecou às 14:30, sob um sol ardente. ${ }^{49}$

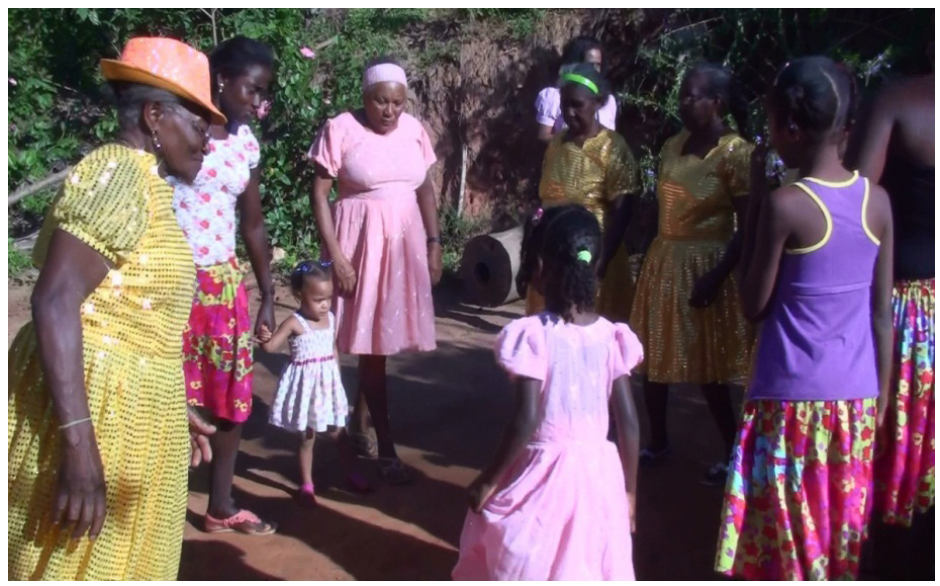

Figura 3: Dona Edite (na esquerda, usando chapéu) e o Grupo de Ciranda e Coco de Roda. Foto de Marília Cahino Bezerra. Junho de 2012.

O Grupo Ciranda e Coco de Roda de Caiana dos Crioulos, coordenado por Dona Edite, é formado por 22 mulheres, que fazem o coro, e três homens como instrumentistas. Os instrumentos utilizados são o zabumba, o triângulo e o ganzá. Além da função de solista e compositora,

48 ARQUIVO Eurides Santos. Caderno de campo Caiana dos Crioulos, p. 17 (manuscrito).

49 ARQUIVO Eurides Santos. Caderno de campo Caiana dos Crioulos, p. 18 (manuscrito). 
Dona Edite confecciona os trajes do grupo, articula e intermedeia as apresentações dentro e fora da comunidade. Durante a semana, ministra aulas de coco de roda e ciranda para as crianças da escola municipal local, onde trabalha há trinta anos como merendeira. As apresentações do grupo, em geral, acontecem no átrio da igreja ou na área de recreio da escola, porque são espaços maiores, próprios para receber os constantes turistas que visitam a comunidade.

Com a roda formada, Dona Edite iniciou o canto "Rosa Rosetá" (Exemplo 4), seguida dos instrumentistas e do coro.

Oh Rosa, roseira,

Oh Rosa, Rosetá.

Menina abra essa roda,

Que o coco vai começar. (bis)

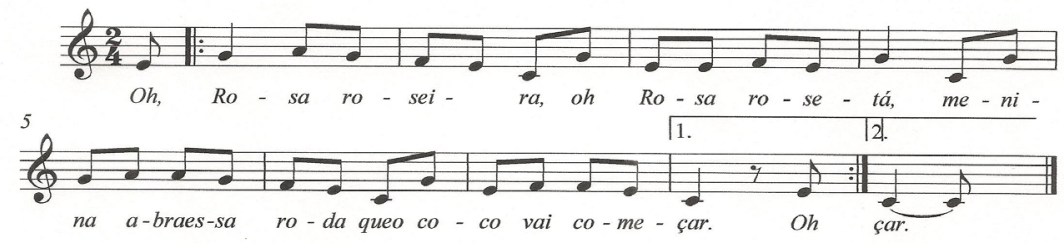

\section{Exemplo 4}

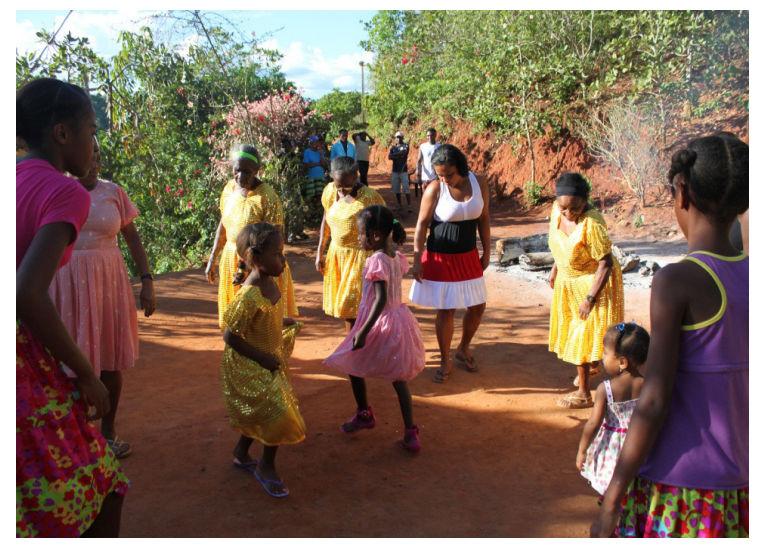

Figura 4: Grupo de Ciranda e Coco de Roda de Caiana dos Crioulos. As netas de Dona Edite aparecem no centro da roda. Foto de Marília Cahino Bezerra. Junho de 2012. 
A brincadeira seguia no terreiro. A cada passo e batida do pé à frente, as dançadoras viravam-se para a parceira logo atrás, simulando o movimento da umbigada ${ }^{50}$, retornando imediatamente para frente, para seguir o sentido da roda. Durante a maior parte do tempo, o olhar das dançadoras se concentrava no movimento dos pés cuja batida no chão levantava a poeira no terreiro. A audiência foi se formando e, ao fim da brincadeira, todos participavam com palmas e conversas ao redor do círculo. À medida que a brincadeira se desenvolvia, a animação tomava conta do ambiente, criando um espaço de interação e alegria, comum a todos ${ }^{51}$.

A disposição mais encontrada para a brincadeira dos cocos é uma roda formada pelo solista e dançadores. Os instrumentistas se posicionam na parte externa. A roda constitui elemento agregador através do qual as pessoas não pertencentes ao grupo, assistentes, transeuntes, conhecedores ou não dos passos e das músicas, se juntam aos brincantes para participar do canto e da dança. O repertório tradicional é o mais utilizado pela maioria dos grupos, havendo constantes variações e improvisos, de forma a adequar as melodias e letras ao evento presente e ao momento da performance.

As letras das músicas versam sobre temas gerais, tais como: amor, amizade, família, culinária, vestuário, devoção aos santos, fatos do cotidiano, acontecimentos históricos (a exemplo do primeiro avião visto no local) e fatos recentes. Em geral, essas letras apontam para regras de conduta - especialmente, nos relacionamentos amorosos, na relação entre pais e filhos, entre vizinhos, apontando para as sanções impostas às situações de desvios. Dois versos da ciranda "Serenou, serená" trazem exemplos dessa realidade quando dizem:

A folha da bananeira

De verde ficou madura

Quem ama mulher casada

Não tem a vida segura.

A laranja de madura

Caiu n'agua, foi ao fundo

Triste da moça solteira

Que cai na boca do mundo.

5o De acordo com Mário de Andrade, a umbigada é uma "coreografia presente em várias danças brasileiras, consistindo na aproximação dos parceiros que se tocam na altura do umbigo (1989, p. 544).

51 ARQUIVO Eurides Santos. Caderno de campo Caiana dos Crioulos, p.22 (manuscrito). 
As canções de agradecimento aos santos e ao público presente constituem parte essencial da sequência das músicas cantadas. Toda brincadeira termina com um canto de despedida:

Despedida de amor faz bem na dor (bis)

Faz chorar, faz chorar,

Faz chorar, faz solucar.

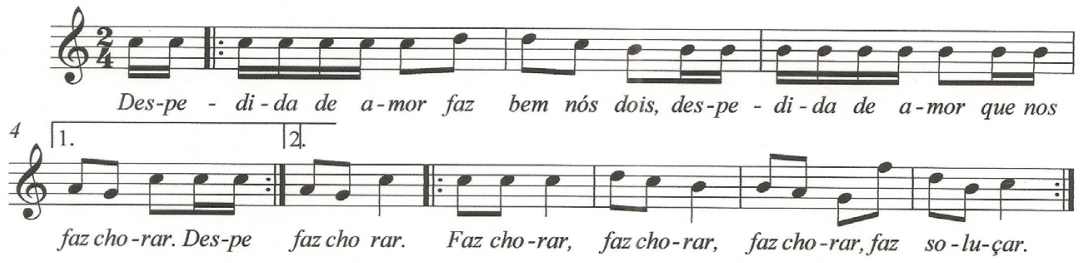

Exemplo 5

Ao fim, Dona Edite agradeceu a presença de todos e os convidou para comerem um bode assado, que havia sido preparado para aquele dia. Na fogueira, as brasas estalavam enquanto assavam o milho do São João ${ }^{52}$.

À guisa de conclusão, a brincadeira dos cocos em Caiana dos Crioulos, como em outros recantos da Paraíba e do Nordeste, coexiste com uma variedade de práticas musicais em contínua disputa e negociação. Por vezes, essa expressão da cultura popular se destaca com certo privilégio no meio midiático, por representar o diferencial que atrai o interesse de um público diferenciado. No ambiente sonoro-musical da comunidade, cirandeiros, sanfoneiros, banda de pífano, entre outros grupos, dividem e compartilham seus espaços com as diversas mídias televisivas, radiofônicas e online, que permitem uma paisagem sonora cotidiana formada por diferentes músicas, definidas pelos diferentes gostos dos moradores.

No contexto da (re)criação das comunidades remanescentes dos quilombos, as performances e os discursos sobre a brincadeira dos cocos se fortalecem e reforçam as reivindicações em torno da questão fundiária e demais lutas sociais locais. Essas lutas são históricas, contínuas e acirradas. No âmbito da brincadeira, especificamente, as políticas públicas de cultura e as novas parcerias estabelecidas com outros grupos do meio

$5^{2}$ ARQUIVO Eurides Santos. Caderno de campo Caiana dos Crioulos, p.22 (manuscrito). 
artístico, cultural e acadêmico constituem fatores essenciais para sua preservação. De toda forma, a 'energia' que mantém a brincadeira dos cocos como uma expressão viva e de valor, diz respeito às crenças e ações do campo da memória social dos seus fazedores. As cirandeiras, como representantes da memória social local, contribuem para a preservação da brincadeira dos cocos, recriando-a através da performance. Elas o fazem não só por terem ouvido e aprendido com os mais velhos, mas por reconhecê-la e saber recriá-la como fato e valor.

\section{Sobre a autora}

\section{Eurides de Souza Santos}

Professora Associada do Departamento de Música da Universidade Federal da Paraíba (UFPB) e etnomusicóloga. E-mail: euridessantos@gmail.com 